\title{
A COMPARATIVE ANALYSIS OF ORGANIZATIONAL ROLE STRESS AMONG THE PRIVATE AND PUBLIC SECTOR BANK OFFICIALS IN JORHAT, ASSAM
}

\author{
Aditi Kejriwal \\ Assistant Professor, Department of Commerce, \\ Jagannath Barooah College, Jorhat, Assam, India
}

\begin{abstract}
Stress becomes an occurrence which is part and parcel in every working sector in the world. The banking sector is not an exception. A bank official on an average spends eight to ten hours on the job under heavy pressure of the various conflicting demands, that too in an alienated and dehumanized environment wherein he is supposed to attain his goals in spite of heavy odds. He needs to perform critical managerial functions in very compelling situations.

Consequently, he is forced to tax his biological limitations, which more often than not results in stress. The study aims to measure the stress level experienced by the public and private sector bank officials based on Pareek's ten role stressors. It also examines the effect of the stress level on the socio-demographic variables. Our methodology entails that 118 public sector and 22 private sector bank officials serving in Jorhat city in the state of Assam. Pareek (1983) Organizational Role Scale (ORS) is adapted to measure the stress level of the bank officials, which reveals that there is no significant difference in the total Organizational Role Stress experienced by the public and private sector bank officials except in some individual role stressors. Further, it is found that there is a significant difference in ORS among bank officials with respect to sociodemographic variables such as their years of service and marital status.
\end{abstract}

Keywords: Organizational role Stress, Level of stress, Bank officials.

Cite this Article: Aditi Kejriwal, A Comparative Analysis of Organizational Role Stress among the Private and Public Sector Bank Officials in Jorhat, Assam, Journal of Management (JOM), 6 (3), 2019, pp. 106-116.

http://www.iaeme.com/JOM/issues.asp?JType=JOM\&VType=6\&IType=3

\section{INTRODUCTION}

Stress becomes a normal phenomenon of present human existence. It is an inevitable accomplishment of the challenges people face in developing new skill, abilities and 
competencies. When the challenges exceed the human capacity to adopt the stress develops. Stress disrupts emotional stability, cognitive functioning and even the body's normal physiological activities. The long term stress is an important factor for development of physical illness, such as heart diseases and high blood pressure. Many major international organizations such as the International Labor Organization and the World Health Organization are addressing issues surrounding workplace stress (Lehrer Andrew Marshall,2005).

The pace at which the change is taking place in the world today is undoubtedly overwhelming and breathtaking. In the fast-changing world of today, everyone experiences stress in their personal as well as professional lives. No individual and no profession are unimpeded from stress. Thus, at present times, stress in general and job stress, in particular, has become a part of normal life and has received substantial attention in modern days. Stress as a phenomenon has been identified in various professions and thus to measure the stress level among bank officials is no exception.

Lazarus (1971) proposed what an interactional definition of stress is. He suggested that "Stress results when demands imposed on an individual is more than his adjustive resources. He further intricated that it depends not only on external conditions but also on the constitutional fragility of the person and the acceptability of his cognitive defensive mechanisms.

Similarly, Cox and McKay (1981) suggested that stress arises when there is an imbalance between the perceived demand and the person's perception of his capability to meet that demand. The system treats stress as an intervening variable, the reflection of a transaction between the person and his environment.

Organizational stress: It is a condition arising from the interaction of people and their jobs and is distinguished by changes within people that force them to deviate from their normal functioning. Organizational or job stress has been defined in terms of misfit between a person's skills and abilities and the demands of his/her job. The concept of organizational stress falls under a broader concept, i.e. 'Role Stress'. According to Pareek (1993), Role signifies the set of functions one performs in retaliation to the expectations of the significant other individuals and one's assumptions from that position or job. The organization and individual come together through a role. Pareek (1983) identified 10 different types of organizational role stresses. Briefly, these are:

1. Inter-Role Distance (IRD): This kind of stress is experienced when there is a conflict between organizational and non-organizational roles.

2. Role Stagnation (RS): This type of stress is the result of a gap between the demand to outgrow a previous role and to engage in new role effectively. It is a feeling of being stuck in the same position. It creates a perception that there are no prospects for one's career progress.

3. Role Expectation Conflict (REC): Different expectations generate this kind of stress by different significant persons about the same role such as conflicting demands originating from colleagues, i.e., superiors, subordinates, and peers in the organization.

4. Role Erosion (RE): This kind of stress is experienced when the role occupants feel that functions that should belong to occupant's role are being transferred or performed or shared by other role occupants. It is a feeling of responsibility without authority. This also happens when, but the credit for the same goes to someone else.

5. Role Overload (RO): This kind of stress emerges when the role occupants feel that too much is expected from the role than what the occupants can cope with. It has two aspects: qualitative and quantitative. 
6. Role Isolation (RI): This role stress refers to the psychological distance between the occupant's role and other roles in the same role set. It is characterized by the feeling that others do not reach out easily, indicative of the absence of a strong linkage of one's role with other roles.

7. Personal Inadequacy (PI): This kind of stress arises when the role occupants feel that he/she does not have the necessary skills or training for effectively performing the functions expected from his/ her role. This happens when the organization do not impact periodical training in order to enable the employees to subsist with the fast changes both within and outside the organization.

8. Self-Role Distance (SRD): This kind of stress is experienced when there is a conflict between one's values and self-concepts with the requirements of the organizational roles.

9. Role Ambiguity (RA): This kind of stress is experienced when there is a lack of clarity about the demands of the role which may arise because of the lack of information or understanding.

10. Resource Inadequacy (RIn): This kind of stress is evident when there is a lack of availability of resources needed for compelling role performances.

Considering the role stress as a debilitating syndrome, it is of paramount importance to understand the causes of role stress among bank professionals for their betterment and formation of stress intervention programmes. The banking sector is one of the key areas of the service sector which is growing very fast in the present decade. The market and customer driven commercial banks have put considerable pressure among the bank officials, especially frontline employees. The front-line officials of the banking industry, who are in crucial positions, endeavour to meet the needs of customers at one end while attempting to fulfil the expectations of managers on the other. This study is undertaken with the purpose to investigate the factors causing role stress amongst bank professionals systematically. The banking sector is among the top ten high-stress workplaces (www.banknet.india.com) in India. This analysis will provide crucial information about the prevalence of specific role stressors at commercial banks. It shall also offer a unique glimpse at the significant public and private sector differences in exposure to the role stressors at the workplace, the studies in which regard are relatively less.

While a lot of studies have been carried out on the psychological fall-out in the present decade by many scholars, there are only a few such studies relating to the banking sector even though this sector is one of those most drastically affected.

\section{OBJECTIVES AND HYPOTHESES}

The objectives of the study are:

- To analyse the difference in stress levels experienced by the bank officials of the public and private sector banks.

- To assess the influence of socio-demographic variables on the respondent's stress level.

To achieve the objectives mentioned above, the following hypotheses have been formulated:

- Null Hypotheses (HO1): There is no significant variation in the status of the stress levels experienced by the public and private bank officials.

- Null Hypotheses (HO2): There is no significant difference in the Organizational Role Stress among the bank officials concerning their age groups.

- Null Hypotheses (HO3): There is no significant difference in the Organizational Role Stress among the bank officials concerning their monthly incomes. 
A Comparative Analysis of Organizational Role Stress among the Private and Public Sector Bank Officials in Jorhat, Assam

- Null Hypotheses (HO4): There is no significant difference in the Organizational Role Stress among the bank officials with respect to their years of experience.

- Null Hypotheses (HO5): There is no significant difference in Organizational Role Stress among the bank officials with respect to their marital status.

- Null Hypotheses (HO6): There is no significant difference in Organizational Role Stress among the bank officials with respect to their educational qualifications.

\section{METHODOLOGY OF THE STUDY}

The nature of the present study is partly descriptive and partly diagnostic. The main source of the data for the study is primary which is generated through a structured questionnaire, and in this sense, it is an empirical study also. The study is based on the bank's officials serving in the Public sector and private sector banks operating in Jorhat city in the state of Assam, India. There are 21 numbers of Public sector banks and 7 numbers of Private sector banks operating in the city. All non-officials are kept outside the purview of this work with a view to having an indepth study on stress among officials. Only one branch of each bank is selected as a sample for the study. Census method is adapted to receiving information from the bank officials in the form of a structured questionnaire which consists of Pareek Scale of ORS besides demographic information. Out of the total of 170 questionnaires served to the officials, 30 numbers were rejected because of incomplete information. As such only 140 questionnaires were accepted for this study, 118 were public sector bank and remaining private sector bank.

The accepted questionnaires are tabulated with the help of a self-designed software and analysis is done through SPSS 16.0 version. Mean values and standard deviations have been calculated to measure the role stresses. It involved the ANOVA technique, t-test for testing the hypothesis. Further, secondary information's are collected from existing literature to have an in-depth study on this topic and gather the knowledge of different research conducted by scholars around the globe.

\section{REVIEW OF LITERATURE}

Occupational stress increasingly gets importance from various researchers. It has been witnessed from the studies conducted in the service sector, which have direct interaction with customer or public more prone to have relatively higher stress levels.

Research conducted by Ganster and Scharebroeck (1991)shows that stress carries significant human costs in terms of mental and physical illness. Experts in Health Sciences and traffic management hold the view that stress causes many physical and mental problems and road accident too. The causative factors include poor time management, leading to rush hour traffic mishaps.

Stress also has significant financial consequences. Further, it has been estimated by the New York Business Group on Health that stress costs employers \$75-80 billion annually on absenteeism, turnover, lost productivity, health and disability claims. The costs of stress to society at large are very substantial. According to an estimate, stress results in 90 per cent of medical disorders.

Cooper \& Payne (1995) indicate that adverse environmental factors are stressor (e.g. work overload, role conflict, poor working conditions) connected with a particular job, determined occupational stress. Stress arises when a coping response cannot be found, i.e. he is not able to cope anymore and as such are not able to get along with his job, and consequently resulting in leaving the organization, increase in absenteeism and grievances. 
Cohen (1991)opines that stress "is brought about when a highly motivated organism is unable to find and cope response to the problem comforting it. This may occur "under conditions variously described as trauma, frustration and conflict".

Associated Chamber of Commerce and Industry of India (ASSOCHAM), in a study conducted in 2007, has also reported that those working in the banking sector - both public and private- tend to get stressed as they have to attract a large pool of customers for various schemes besides ensuring timely recovery of loans (www.assocham.org/prels). This study will provide some important information about the prevalence of specific role stressors at commercial banks. It shall also offer a unique glimpse at the significant public and private sector differences in exposure to the role stressors at the workplace.

Research conducted by the National Safety Council, the College of Insurance, and the National Institute for Occupational Safety and Health 1 in the United States of America reveals the magnitude of organizational costs associated with stress.

Approximately 75 to 80 per cent of all industrial accidents are caused by an inability to cope with stress, and cost US companies in excess of $\$ 32$ billion annually.

Heart disease - associated with stress is responsible for an annual loss of more than 185 million workdays.

Stress-related headaches are the leading cause of lost work hours in American companies.

Psychological or psychosomatic problems contribute to more than 60 per cent of long- term employee disability cases, and $\$ 26$ billion is spent annually on disability payments and medical bills.

Though estimates and projections such as these should be treated cautiously, there is no doubt, however, that the consequences of excessive stress are significant in both individual and organizational terms. Executive stress is one of the most debilitating personal and medical problems of a modern complex organization.

Sabir et al. (2003) observed that more significant interaction with an electronic device such as a computer, Central Processing System are the stressors of the present era.

Lahal (2007) observed that the job satisfaction level is negatively affected as a result of the organisational role stress.

In a study conducted by Modekurti and Chattopadhyay (2008) reveals that working women experienced a higher stress level for additional responsibilities in order to maintain work-life stability.

In an empirical study conducted by Gupta.el.al. (2008) on civil hospital nurses in West Bengal revealed that role erosion was the most prominent role stressor.

The study conducted by Chandraiah, K, Agarwal, S.C. Marimuthu, P. Monoharan, N. (2003) on "Effect of organisational stress and job satisfaction among managers" revealed that a higher level of job stress and reduced job satisfaction among managers. The study also indicates that age is negatively co-related with occupational stress and positively correlated with job satisfaction.

Arbu. K. (1995) in his study "A study on the role stress of Supervisors in Textile industries" showed that there were inherent problems in the performance of the role. The study also revealed that there was a significant positive relationship between role stress and performance of supervisors in the textile industry.

Winefield Anthony H, Gillespie Nicole, Stough Con, DuaJagdish and Hapuarachchi John (2002) in their study on "Occupational stress in Australian Universities" revealed that the staff of Australian Universities particularly the academic staff were highly stressed. It also pointed 
A Comparative Analysis of Organizational Role Stress among the Private and Public Sector Bank Officials in Jorhat, Assam

out that the team of Australian Universities suffered psychological illness due to occupational stress.

The study conducted by PawarSurg Capt., AA Rathod J. (2007) on "Occupational Stress in Naval Personnel" showed that naval personnel serving on board submarine and ship had a lower level of occupational stress in contrast to those serving on shore establishments. It also revealed that the occupational stress level of the junior sailors level was higher.

Emith Andrew, Brice Carolyn, Collins Alison, Mathews Victoria \& McNamara Rachel (2000) in the study "The scale of Occupational Stress: A further analysis of the impact of Demographic factors and type of job" described the impact of demographic and occupational variables on reported stress at work. The analysis revealed that the scale of occupational stress would vary as a function of demographic and professional factors.

The study conducted by Nair Sreedhar P. and Joseph Tharsis (2007) on "The DuoDimensional Hypothesis of Stress" revealed certain advantages of stress. It found that during the stress time, the worker released some amount of hormones and it helped the execution of the task.

Emsley (2003) in his research study "Multiple goals and job-related tension and Performance" suggested that job-related tension and Performance deteriorate as managers pursue multiple goals although the relationship seems to be non- linear. The relative importance of goals does not appear to be necessary.

Aziz (2003) investigated the prevalence of occupational role stress among IT professionals. Resource inadequacy emerged as the most prominent stressor. The study reported more stress among men as compared to women.

The review of the literature provided an important model and empirical foundation for this study. It also validated the relevance of the variables to attain the objectives of the study.

\section{DATA ANALYSIS AND INTERPRETATION}

Table 1 Reliability Statistics Cronbach's Alpha

\begin{tabular}{|c|c|}
\hline $\begin{array}{c}\text { Cronbach's } \\
\text { Alpha }\end{array}$ & N of Items \\
\hline .934 & 10 \\
\hline
\end{tabular}

Table 1 reveals that the Cronbach's Alpha value for the Organisational Role Stress (ORS) Scale used is 0.934 indicating that the scale is highly reliable for the study.

Table 2 Status of Role Stressors

\begin{tabular}{|l|c|c|c|}
\hline \multicolumn{1}{|c|}{ Role Stressors } & Mean & SD & Rank \\
\hline Inter Role Distance & 9.09 & 4.692 & 1 \\
\hline Role Stagnation & 7.21 & 4.176 & 3 \\
\hline $\begin{array}{l}\text { Role Expectation } \\
\text { Conflict }\end{array}$ & 6.47 & 4.116 & 5 \\
\hline Role Erosion & 6.16 & 3.678 & 9 \\
\hline Role Overload & 7.5 & 4.497 & 2 \\
\hline Role Isolation & 6.3 & 3.925 & 8 \\
\hline Personal Inadequacy & 6.36 & 3.859 & 6 \\
\hline Self-Role Distance & 6.71 & 3.788 & 4 \\
\hline Role Ambiguity & 5.61 & 4.071 & 10 \\
\hline Resource Inadequacy & 6.33 & 4.156 & 7 \\
\hline
\end{tabular}


As revealed by the table 2, inter-role distance is the leading role stressor experienced by the bank officials escorted by role overload and role stagnation successively. The least experienced stressor emerged out to be role ambiguity.

Table 3 Comparative between the level of stress experienced by public and private sector employees

\begin{tabular}{|l|c|c|c|c|c|}
\hline \multirow{2}{*}{ Stressor } & \multicolumn{2}{|c|}{ Public Sector } & \multicolumn{2}{c|}{ Private Sector } & Sig \\
\cline { 2 - 5 } & Mean & SD & Mean & SD & Value \\
\hline Inter Role Distance & 12.05 & 4.74 & 9.73 & 2.921 & $0.000^{* *}$ \\
\hline Role Stagnation & 8.84 & 4.363 & 7.86 & 3.314 & $0.000^{* *}$ \\
\hline Role Expectation Conflict & 7.71 & 4.612 & 7.34 & 3.591 & 0.202 \\
\hline Role Erosion & 6.93 & 4.082 & 6.6 & 3.447 & 0.210 \\
\hline Role Overload & 9.57 & 4.763 & 7.22 & 3.576 & $0.000^{* *}$ \\
\hline Role Isolation & 7.4 & 4.291 & 7.06 & 3.046 & 0.190 \\
\hline Personal Inadequacy & 7.34 & 4.038 & 7.02 & 3.619 & 0.225 \\
\hline Self-Role Distance & 7.44 & 3.858 & 8.31 & 3.482 & $0.000^{* *}$ \\
\hline Role Ambiguity & 6.29 & 4.539 & 6.85 & 3.244 & $0.045^{*}$ \\
\hline Resource Inadequacy & 7.65 & 4.532 & 7.35 & 3.716 & 0.287 \\
\hline Total ORS & 67.78 & 34.21 & 67.63 & 27.76 & 0.980 \\
\hline
\end{tabular}

Note: ** significant at $99 \%$ confidence level

*significant at $95 \%$ confidence level

Calculation of the mean, standard deviation and t-test values for each role stressors aids us to make a comparison of the level of stress among the public and private sector bank officials. Table 3 reveals that there is no significant difference in the total Organizational Role Stress experienced by the public and private sector bank officials and such, HO1 is an acceptable hypothesis.

However, a comprehensive analysis of the above table unveils that there is a significant difference between the two sectors in terms of employees' stress levels when it comes to individual role stressors such as inter-role distance, role stagnation, role overload, self-role distance and role ambiguity.

Table 4 Segregation of the level of stress among the private and public bank officials

\begin{tabular}{|c|c|c|c|c|c|c|c|c|c|c|c|c|c|c|c|c|}
\hline \multirow{3}{*}{$\begin{array}{c}\text { Role } \\
\text { Stressors }\end{array}$} & \multicolumn{4}{|c|}{ Low Stress } & \multicolumn{4}{|c|}{ Medium Stress } & \multicolumn{4}{|c|}{ High Stress } & \multicolumn{4}{|c|}{ Very High Stress } \\
\hline & \multicolumn{2}{|c|}{ Private } & \multicolumn{2}{|c|}{ Public } & \multicolumn{2}{|c|}{ Private } & \multicolumn{2}{|c|}{ Public } & \multicolumn{2}{|c|}{ Private } & \multicolumn{2}{|c|}{ Public } & \multicolumn{2}{|c|}{ Private } & \multicolumn{2}{|c|}{ Public } \\
\hline & $\mathbf{F}$ & $\%$ & $\mathbf{F}$ & $\%$ & f & $\%$ & f & $\%$ & $\mathbf{f}$ & $\%$ & f & $\%$ & $\mathbf{f}$ & $\%$ & $\mathbf{f}$ & $\%$ \\
\hline $\begin{array}{l}\text { Inter Role } \\
\text { Distance }\end{array}$ & 9 & 23.68 & 25 & 24.5 & ${ }^{\prime} 19$ & 50 & 39 & 38.23 & 10 & 26.31 & 26 & 25.49 & 0 & 0 & 12 & 11.8 \\
\hline $\begin{array}{l}\text { Role } \\
\text { Stagnation }\end{array}$ & 13 & 34.21 & 42 & 41.17 & 17 & 44.73 & 34 & 33.33 & 8 & 21.05 & 21 & 20.58 & 0 & 0 & 5 & 4.9 \\
\hline $\begin{array}{l}\text { Role } \\
\text { Expectation } \\
\text { Conflict }\end{array}$ & 11 & 28.94 & 45 & 44.11 & 21 & 55.26 & 41 & 40.19 & 5 & 13.15 & 13 & 12.74 & 1 & 2.63 & 3 & 2.94 \\
\hline Role Erosion & 18 & 47.36 & 46 & 45.09 & 16 & 42.1 & 41 & 40.19 & 4 & 10.52 & 13 & 12.74 & 0 & 0 & 2 & 1.96 \\
\hline $\begin{array}{l}\text { Role } \\
\text { Overload }\end{array}$ & $\overline{16}$ & 42.1 & 34 & 33.33 & 18 & 47.36 & 42 & 41.17 & 4 & 10.52 & 19 & 18.62 & 0 & 0 & 7 & 6.86 \\
\hline Role Isolation & 12 & 31.57 & 53 & 51.96 & 22 & 57.89 & 33 & 32.35 & 4 & 10.52 & 14 & 13.72 & 0 & 0 & 2 & 1.96 \\
\hline $\begin{array}{l}\text { Personal } \\
\text { Inadequacy }\end{array}$ & 14 & 36.84 & 43 & 42.15 & 18 & 47.36 & 41 & 40.19 & 6 & 15.78 & 16 & 15.68 & 0 & 0 & 2 & 1.96 \\
\hline $\begin{array}{l}\text { Self-Role } \\
\text { Distance }\end{array}$ & 12 & 31.57 & 42 & 41.17 & 17 & 44.73 & 44 & 43.13 & 8 & 21.05 & 14 & 13.72 & 1 & 2.63 & 2 & 1.96 \\
\hline $\begin{array}{l}\text { Role } \\
\text { Ambiguity }\end{array}$ & 12 & 31.57 & 56 & 54.9 & 23 & 60.52 & 36 & 35.29 & 3 & 7.89 & 6 & 5.88 & 0 & 0 & 4 & 3.92 \\
\hline $\begin{array}{l}\text { Resource } \\
\text { Inadequacy }\end{array}$ & 15 & 39.47 & 50 & 49.01 & 17 & 44.73 & 37 & 36.27 & 6 & 15.78 & 11 & 10.78 & 0 & 0 & 4 & 3.92 \\
\hline
\end{tabular}


A Comparative Analysis of Organizational Role Stress among the Private and Public Sector Bank Officials in Jorhat, Assam

For a comprehensive analysis of the difference in stress levels among the private and public bank officials, the ORS scores on various stressors have been categorized into four groups, namely Low Stress Group (0-5), Medium Stress Group (6-10), High Stress Group (11-15) and Very High Stress Group (16-20).

As depicted by the above table, more than half of the public sector bank officials respond to role ambiguity as a "low-stress category" whereas the majority of the private sector bank officials respond to role erosion as a "low-stress category". Almost three-fifths of the private sector bank officials respond to role ambiguity as a "medium stress category" whereas the majority of the public sector officials respond to self- role distance as a "medium category stressor". Almost one- fourth of the private and public sector bank officials respond to interrole distance as a "high-stress category stressor". Only $1 \%$ of the private sector bank officials respond to role expectation conflict and self- role distance as a "very high-stress category" whereas approximately $12 \%$ of the public sector bank officials respond to inter-role distance as a "very high-stress category".

Further to assess the influence of demographic variables on the respondent's stress level, the following table is prepared which classifies the bank officials based on the selected variables.

Table 5 Socio-demographic profile of the respondent

\begin{tabular}{|l|l|c|}
\hline \multicolumn{1}{|c|}{$\begin{array}{c}\text { Socio- demographic } \\
\text { variables }\end{array}$} & \multicolumn{1}{c|}{ Groups } & No. of Respondents \\
\hline \multirow{4}{*}{ Age } & A. Upto 30 years & 38 \\
\cline { 2 - 3 } & B. 30-40 years & 50 \\
\cline { 2 - 3 } & C. 40-50 years & 26 \\
\cline { 2 - 3 } & D. 50 years and above & 26 \\
\hline \multirow{4}{*}{ Monthly Income } & A. Below Rs. 1,00,000 & 93 \\
\cline { 2 - 3 } & $\begin{array}{l}\text { B. Rs. 1,00,000 - Rs. } \\
\text { 2,00,000 }\end{array}$ \\
\cline { 2 - 3 } & C. Rs. 2,00,000 and above & 24 \\
\hline \multirow{5}{*}{ Years of experience } & A. Below 3 years & 23 \\
\cline { 2 - 3 } & B. 3-7 years & 30 \\
\cline { 2 - 3 } & C. 7-10 years & 27 \\
\cline { 2 - 3 } & D. 10 years and above & 38 \\
\hline \multirow{2}{*}{ Marital Status } & A. Unmarried & 45 \\
\hline \multirow{2}{*}{ Educational Qualification } & B. Married & 22 \\
\cline { 2 - 3 } & A. Graduate and below & 62 \\
\cline { 2 - 3 } & B. Post- Graduate and above & 78 \\
\hline
\end{tabular}

Table 6 Impact of socio-demographic variables on the total organizational role stress

\begin{tabular}{|l|l|l|l|l|}
\hline Hypothesis & Total Stress & $\begin{array}{l}\text { Socio- Demographic } \\
\text { Variables }\end{array}$ & $\begin{array}{l}\text { Sig } \\
\text { Value }\end{array}$ & Remarks \\
\hline HO2 & ORS & Age Group & 0.842 & Accepted \\
\hline HO3 & ORS & Monthly Income & 0.567 & Accepted \\
\hline HO4 & ORS & Years of experience & $0.000^{* *}$ & Not Accepted \\
\hline HO5 & ORS & Marital Status & $0.002^{*}$ & Not Accepted \\
\hline HO6 & ORS & $\begin{array}{l}\text { Educational } \\
\text { Qualification }\end{array}$ & 0.186 & Accepted \\
\hline
\end{tabular}

Note: ** significant at $99 \%$ confidence level

$*$ significant at $95 \%$ confidence level 
We use the ANOVA technique to test the null hypothesis $\mathrm{HO} 2, \mathrm{HO} 3$ and $\mathrm{HO} 4$ and independent sample t-test are used to test HO5 and HO6.

Table 6 reveals that there is no significant difference between the total Organizational Role Stress among the bank officials of different age groups and as such $\mathrm{HO} 2$ is an acceptable hypothesis.

Similarly, running an ANOVA test unveils that there is no significant difference between the total Organizational Role Stress among the bank officials with respect to their monthly income and hence, $\mathrm{HO} 3$ is an acceptable hypothesis.

Again, ANOVA test has been used to analyze the impact of years of experience on the employees' total stress level, and there emerged out to be a significant difference in the ORS with respect to their years of experience. Hence, $\mathrm{HO} 4$ which states that there is no significant difference in the Organizational Role Stress with respect to their years of experience is not an acceptable hypothesis.

Independent sample t-test has been used to analyze the influence of marital status of the employees on their stress level. As depicted by the above table, there emerged out to be a significant difference in the ORS with respect to their marital status. As such, HO5 which states that there is no significant difference in the Organizational Role Stress with respect to their marital status is not an acceptable hypothesis.

In order to examine the impact of educational qualification on the employees' stress level, independent sample t-test has been used, and it was found that there is no significant difference in the Organizational Role Stress with respect to their educational qualification. Hence, HO6 is an acceptable hypothesis.

Table 7 Impact of 'years of experience' on the Total Organizational Role Stress

\begin{tabular}{|l|c|c|c|}
\hline \multicolumn{1}{|c|}{ Years of experience } & Mean & $\begin{array}{c}\text { Standard } \\
\text { Deviation }\end{array}$ & $\begin{array}{c}\text { Sig } \\
\text { value }\end{array}$ \\
\hline A. Below 3 years & 50.76 & 28.61 & \multirow{2}{*}{$.000^{* *}$} \\
\hline B. 3-7 years & 54.85 & 23.98 & \\
\hline C. 7-10 years & 64.76 & 27.4 & \\
\hline D. 10 years and above & 89.31 & 32.28 & \\
\hline
\end{tabular}

Note: $* *$ significant at $99 \%$ confidence level

Since there emerged out to be a significant difference in the ORS of the bank officials with respect to their years of experience, further analysis is made to examine which group of employees face a high level of stress. As revealed through table 7, employees with more years of experience are endowed with more responsibilities and hence with higher role stress as compared to the employees with lesser years of experience.

Table 8 Impact of 'marital status' on the Total Organizational Role Stress

\begin{tabular}{|l|c|c|c|}
\hline \multicolumn{1}{|c|}{ Marital Status } & Mean & $\begin{array}{c}\text { Standard } \\
\text { Deviation }\end{array}$ & $\begin{array}{c}\text { Sig } \\
\text { Value }\end{array}$ \\
\hline A. Unmarried & 47.95 & 35.95 & \multirow{2}{*}{$0.002 *$} \\
\hline B. Married & 71.43 & 30.57 & \\
\hline
\end{tabular}

Note: *significant at $95 \%$ confidence level

As there has been observed a significant difference in the Organizational Role Stress among the bank officials with respect to their marital status, further analysis is made to investigate which group of employees whether married or unmarried officials encounters higher stressful role. As the above table unveils, married bank officials experience higher organizational role stress as compared to unmarried officials. 
A Comparative Analysis of Organizational Role Stress among the Private and Public Sector Bank Officials in Jorhat, Assam

\section{CONCLUSION}

The present study has led to the conclusion that there is no significant difference in the total Organizational Role Stress experienced by public and private sector bank officials. However, in some individual role stressors such as inter- role distance, role stagnation, role overload, selfrole distance and role ambiguity, there has been found significant differences amongst the bank officials of public and private sector.

Further, on examining the impact of socio- demographic variables on the respondent's stress level, it has been revealed that there is no significant difference in Organizational Role Stress among the bank officials with respect to variables such as age, monthly income and educational qualification. However, the study reveals that there is a significant difference in ORS among bank officials with respect to their years of service and marital status. Employees with more years of service encounter higher stress as compared to employees with lesser years of experience perhaps because the former employees are endowed with more responsibilities. Also, married bank officials experience a higher role stress as compared to unmarried official.

It is suggested that efforts are imperative to relieve role stress by focusing on communication, concentrating on group support building and the improvement of individual communication skills. Openness, by means of communication at work shall also clarify and sort the conflicting expectations in the role.

\section{REFERENCES}

[1] Arbu, K (1995): A study on the role stress of Supervisors in Textile Industry, PhD Dissertation (Unpublished), P.S.G College of Arts and Science, Coimbatore.

[2] Aziz, M (2003) "Organizational Role Stress among Indian information technology professionals" Asian Pacific Newsletter on Occupational Health and safety, Vol, 10, pp. 3133

[3] Chandraiah, K, Agarwal, S.C. Marimuthu, P. Monoharan, N. (2003) on " Occupational stress and job satisfaction among managers" Indian Journal of Occupational and Environmental Medicine, Vol.7, No, 2, PP 6-11

[4] Cl Randhawa, DS, (2004) "Soldier and Stress Level” Pratividrohi, CIJW School. March, pp 28-31.

[5] Cohen, D.A. Tyrell, \& Smith,A., "Psychological Stress and Susceptibilility to the Common Cold" New England Journal of Medicine,1991, pp, 606-612.

[6] Cooper. \& Payne, "Coping and Consequences of Stress at Work,"1995

[7] Cox, T. And Mackay, C.J. (1981): "A transactional Approach to Occupational Stress". In E.N. Corlett and J. Richardson (Eds.), Stress, Work Design and Productivity, pp 91-113, New York: Wiley.

[8] Emsley, (2003) "Multiple goals and managers' job-related tension and performance", Journal of Managerial Psychology, Vol. 18 Issue: 4, pp. 345-356

[9] Ganster .D.C. and Scharebroeck.J. (1991) “Work Stress and employees health, ” Journal of Management ,17, ,pp.235-271.

[10] Lazarus, R.S. (1971): “The concept of Stress and Disease.” In L. Levi 9Ed.) Society, Stress and Disease, pp53-58. London, oxford University Press

[11] Lehal, Ritu; and Singh, Sukhdeep (2005), "Organizational Role Stress among College Teachers of Patiala District: A Comparative Study of Government and Private Colleges," RIMT Journal of Strategic Management \& Information Technology, Vol. 2, No.1 \& 2, Jan.June 
[12] Nair Sreedhar P. and Joseph Tharsis (2007) on "The Duo- Dimensional Hypothesis of Stress", Effective Executive, Vol. IX, No.8, PP. 44-48, www.icaipress.org

[13] Pareek, U. (1983): Organizational role Stress Scale. ORS Scale Booklet, Answer Sheet and Manual. Ahmedabad: Navin Publications

[14] Pawar Surg Capt., A.A Rathod J. (2007) on "Occupational Stress in Naval Personnel", Medical Journal Armed Forces India, MJAFI, Vol, 63, No, 2, PP, 154-156, http/www.mjafi.org

[15] Selye, Hans. (1978). "The general adaptation syndrome and the disease of adaptation." Journal of clinical endocrinology.

[16] Smith Andrew, Brice Carolyn, Collins Alison, Mathews Victoria \& McNamara Rachel (2000) in the study "The scale of Occupational Stress: A further analysis of the Impact of Demographic Factors and Type of Job", Contract Research Report 3112000, Center for Occupational and Health Psychology School of Psychology, Cardiff University, Cardiff, http:/www.cardiff.ac.uk

[17] Winefield Anthony H, Gillespie Nicole, Stough Con, Dua Jagdish and Hapuarachchi John (2002) 'Occupational Stress in Australian Universities', National Tertiary Education Union, Australia, http/www.backingaustraliasfuture.gov.au 